\title{
ESTIMASI KANDUNGAN KARBON BIOMASA PNEUMATOFOR Avicennia marina
}

\author{
(Estimation Of Carbon Content In Avicennia Marina Pneumatophores Biomass)
}

Gilbert Kindangen $^{1^{*}}$, Calvyn F.A. Sondak ${ }^{2}$, Deislie R.H. Kumampung ${ }^{2}$, Grevo S. Gerung ${ }^{2}$, James J.H. Paulus ${ }^{2}$, Billy Th. Wagey2, Sipriana S. Tumembouw ${ }^{3}$

1. Mahasiswa Program Studi IImu Kelautan, FPIK, UNSRAT Manado

2. Staf Pengajar Program Studi IImu Kelautan, FPIK, UNSRAT Manado

3. Staf Pengajar Program Studi Budidaya Perairan, FPIK UNSRAT Manado

Penulis korespondensi: Gilbert Nick Kindangen; gilbertkindangen22@gmail.com

\begin{abstract}
Mangrove forests play an important role in mitigating the effects of global warming as mangroves can absorbs and stores carbon therefor, mangrove plants including $A$. marina can act as carbon sinks. The study aim is to estimate the carbon content contained in A. marina pneumatophore biomass. The data was taken $b$ using line transect method. The number of research stations are 3 stations contain 3 plots $\left(10 \times 10 \mathrm{~m}^{2}\right)$ for each station. Samples were taken at low tide by established 3 microplots $\left(50 \times 50 \mathrm{~cm}^{2}\right)$ in each $10 \times 10 \mathrm{~m}^{2}$ plots. The results showed that the highest biomass value was found at Station 3 of $0.49 \mathrm{Kg} / \mathrm{m}^{2}$, followed by Station 1 of $0.42 \mathrm{Kg} / \mathrm{m}^{2}$, and the least pneumatophore biomass value was found at Station 2 of $0.41 \mathrm{Kg} / \mathrm{m}^{2}$. This finding is in line to the potenntial potential carbon content in pneumatophores where Station 3 has $\mathrm{C}$ content $\left(0.08 \mathrm{Kg} \mathrm{C} / \mathrm{m}^{2}\right)$, dand $0.07 \mathrm{Kg} \mathrm{C} / \mathrm{m}^{2}$ for both station 1 and 2 respectively. The average of $C$ Contain in pneumatphores was $0.28 \mathrm{Kg} \mathrm{C} / \mathrm{m}^{2}$.
\end{abstract}

Keyword : Carbon Content, Biomass, Pneumatophores, Avicennia marina

\section{ABSTRAK}

Hutan mangrove berperan penting dalam upaya mitigasi akibat dari pemanasan global karena mangrove dapat berfungsi sebagai penyerap dan penyimpan karbon. Oleh karena itu tanaman mangrove termasuk $A$. marina dapat berperan sebagai penyerap karbon, sehingga bila kita melakukan penambahan jumlah tanaman maka akan meningkatkan daya serap karbon atau pengurangan jumlah karbon di atmosfir $A$. marina yang merupakan spesies yang mempunyai kemampuan yang baik dalam menyerap dan menyimpan karbon. Penelitian ini bertujuan untuk mengestimasi kandungan karbon yang terdapat dalam biomasa pneumatofor Avicennia marina di Desa Darunu Kecamatan Wori dengan menggunakan metode kuadrat. Jumlah stasiun penelitian adalah 3 stasiun dengan 3 plot ukuran $10 \times 10 \mathrm{~m}^{2}$ untuk setiap stasiun. Sampel diambil pada saat air surut dengan membuat 3 mikroplot $\left(50 \times 50 \mathrm{~cm}^{2}\right)$ di dalam plot $10 \times 10 \mathrm{~m}^{2}$. Hasil penelitian diperoleh nilai biomasa paling tinggi terdapat di Stasiun (3) sebanyak $0,49 \mathrm{Kg} \mathrm{C} / \mathrm{m}^{2}$, sedangkan pada stasiun (1) sebanyak $0,42 \mathrm{Kg} \mathrm{m}^{2}$, nilai biomasa pneumatofor paling sedikit terdapat di Stasiun (2) sebanyak $0,41 \mathrm{Kg} \mathrm{\textrm {m } ^ { 2 }}$. Sehingga hasil estimasi potensi kandungan karbon pneumatofor paling tinggi terdapat di Stasiun 3 sebanyak $0,08 \mathrm{Kg} \mathrm{C} / \mathrm{m}^{2}$, Sedangkan karbon biomasa mangrove paling sedikit terdapat pada 2 stasiun yaitu stasiun 1 dan 2 sebanyak $0,07 \mathrm{Kg}$ $\mathrm{m}^{2}$. Rata-rata kandungan karbon di dalam biomasa pneumatofor adalah $0.28 \mathrm{Kg} \mathrm{C} / \mathrm{m}^{2}$.

Kata kunci; Kandungan Karbon, Biomasa, Pneumatofor, Avicennia marina 


\section{PENDAHULUAN}

Hutan mangrove merupakan salah satu bentuk ekosistem hutan yang unik dan khas, terdapat di daerah pasang surut di wilayah pesisir, pantai, dan pulau-pulau kecil serta merupakan sumber daya alam yang sangat potensial. Hutan mangrove memiliki nilai ekonomis dan ekologis yang tinggi (Dahuri, et al. 1996).

Hutan yang paling dekat dengan laut sebagian besar didominasi oleh spesies Avicennia spp. Bagian pinggir Avicennia biasanya sempit, karena benih Avicennia tidak dapat tumbuh dengan baik pada keadaan yang teduh dan berlumpur tebal yang biasanya terdapat di dalam hutan. Tumbuhan yang tumbuh didaerah tersebut biasanya dapat beradaptasi dengan salinitas tinggi (Kordi dan Ghufron, 2012).

Masyarakat mengenal Avicennia marina sebagai api-api putih. A. marina merupakan tumbuhan pionir pada lahan pantai yang terlindung, memiliki kemampuan tumbuh pada berbagai habitat pasang surut, bahkan ditempat asin sekalipun. Jenis ini merupakan salah satu jenis tumbuhan yang paling umum ditemukan di daerah pasang surut (Halidah, 2014).

Perubahan iklim adalah perubahan yang disebabkan oleh aktivitas manusia baik secara langsung maupun tidak langsung yang mengubah komposisi atmosfer secara global dan mengakibatkan perubahan variasi iklim yang dapat diamati dan dibandingkan selama kurun waktu tertentu (UNFCC, 2015). Isu perubahan iklim berhubungan dengan meningkatnya suhu atmosfir yang disebabkan oleh "Efek Rumah Kaca" yang terjadi karena meningkatnya gasgas rumah kaca. Salah satu gas yang menyebabkan hal itu adalah karbondioksida $\left(\mathrm{CO}_{2}\right)$. Suhu rata-rata permukaan bumi selama 1 abad yang lalu telah meningkat sebesar 1,3 derajat F (IPCC, 2007).

Jika dikaitkan peningkatan $\mathrm{CO}_{2}$ dengan kemampuan tanaman berklorofil maka dalam proses fotosintesis, tanaman membutuhkan energi cahaya, air, dan $\mathrm{CO}_{2}$ untuk membentuk karbohidrat. Dengan demikian terjadinya penyerapan karbon dari udara dan terakumulasi dalam tubuh tanaman dalam bentuk batang, cabang, ranting, daun, bunga, buah, akar, dan tanah. Proses ini biasanya dikenal dengan istilah Carbon Sequestration (EPA, 2008; Jana et al, 2009).

A. marina dapat berperan sebagai penyerap karbon, sehingga bila kita melakukan penambahan jumlah tanaman maka akan meningkatkan daya serap karbon atau pengurangan jumlah karbon di atmosfir. Karena itu perlu dilakukan upaya untuk mengurangi kandungan karbon, salah satunya dapat dilakukan dengan peningkatan populasi tanaman (Kathiresan $d k k$., 2013). Peningkatan $\mathrm{CO}_{2}$ oleh tanaman akan dimanfaatkan dalam proses fotosintesis, dimana $\mathrm{CO}_{2}$ akan diserap dan diubah menjadi karbon organik dalam bentuk biomasa (Windhusari et al., 2012).

Penelitian tentang estimasi kandungan $\mathrm{C}$ di mangrove khususnya di Sulawesi Utara masih sangat sedikit dan umumnya dilakukan pada biomasa pohon (Sondak, 2015: Bachmid dkk. 2017: Bachmid dkk. 2020). Tiolong $d k k$, 2019). Serasah (Tidore $d k k$. 2018) dan sedimen (Verisandria dkk. 2018). Penelitisn inimerupakan yang pertama dilakukan di Sulawesi Utara dalam mengestimasikandungan $\quad \mathrm{C}$ pada pneumatofor A. marina. A. marina yang merupakan spesies yang mempunyai kemampuan yang baik dalam menyerap dan menyimpan karbon. $A$. marina mempunyai kemampuan $75 \%$ lebih cepat dalam menyerap karbon dibandingkan dengan Rhizophora mucronata (Kathiresan dkk., 2013).

Akar merupakan komponen penting dalam siklus karbon dalam ekosistem mangrove (Eshel and Grunzweig, 2012) Berbagai komponen tajuk mangrove berkaitan erat dengan biomasa akar.

Penelitian tentang estimasi simpanan karbon oleh pneumatofor $A$. marina di kawasan mangrove Desa Darunu sangat penting karena dengan mengetahui jumlah kandungan karbon yang mampu disimpan oleh mangrove dapat membantu dalam upaya mitigasi karbondioksida dan upaya konservasi mangrove. Oleh karena itu, tujuan penelitian ini yaitu untuk mengestimasi 
kandungan karbon yang terdapat dalam biomasa pneumatofor A. marina.

\section{METODE}

\section{Lokasi Pengambilan Sampel}

Sampel pneumatofor diambil di Desa Darunu, Kecamatan Wori, Kabupaten Minahasa Utara, Sulawesi Utara pada titik koordinat $1^{\circ} 38^{\circ} 40.99 ” N 124^{\circ} 54^{\circ} 02.42 ” E$. (Gambar 1).

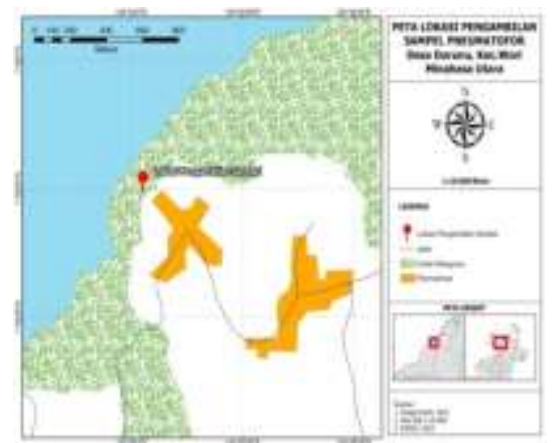

Gambar 1. Peta Lokasi Pengambilan Sampel

\section{Pengambilan Sampel Akar Avicennia Marina}

Pengambilan sampel akar $A$. marina dilakukan dengan menggunakan metode line transek kuadrat (Kauffman dan Donato 2011: Howard, et al. 2015). Jumlah stasiun penelitian adalah 3 stasiun dengan 3 plot ukuran $10 \times 10 \mathrm{~m}^{2}$ untuk setiap stasiun. Sampel diambil pada saat air surut dengan membuat 3 mikroplot $\left(50 \times 50 \mathrm{~cm}^{2}\right)$ di dalam setiap plot $10 \times 10 \mathrm{~m}^{2}$. Semua pneumatofor yang ada di dalam mikroplot akan dihitung jumlahnya. Untuk data biomasa pada setiap mikroplot diambil sampel pneumatofor dengan cara dipotong sampai pada bagian dasarnya dan diambil sebanyak 20-60 sampel. Hal yang sama dilakukan pada mikroplot berikutnya.

\section{Proses Pengeringan Pneumatofor}

Sebelum pneumatofor di keringkan, pertama di cuci terlebih dahulu untuk membersihkan lumpur yang menempel kemudian ditimbang satu per satu untuk mengetahui berat basah. Selanjutnya setelah ditimbang dan diketahui berat basah, pneumatofor kemudian dikeringkan menggunakan oven dengan suhu $80^{\circ} \mathrm{C}$ dilakukan bertahap selama 48 jam. Setiap 8 jam, pneumatofor dikeluarkan dari oven dan di timbang satu per satu.

\section{Analisis Data}

Biomasa pneumatofor akan di hitung dengan menggunakan rumus:

\section{Persamaan 1}

Pengukuran biomasa pneumatofor akan dilakukan dengan cara menimbang berat kering pneumatofor. Berat kering (persamaan 1) ditentukan dengan menggunakan persamaan Howard, et al. (2014):

Total Berat Kering
$(\mathrm{BK})=\frac{\text { Berat Kering }(\mathrm{gram})}{\text { Berat Basah }(\mathrm{gram})} \times$ Total Berat basah

Keterangan: Bk: Berat kering (gram)

Persamaan 2

$\mathrm{Bb}$ : Berat basah (gram)

Biomasa pneumatofor ditentukan dengan cara rata-rata berat kering sampel pneumatofor dikalikan dengan jumlah pneumatofor yang ada di dalam mikroplot.

Biomasa pneumatofor $(\mathrm{kg})$ = Rata-rata berat kering sampel pneumatofor $x$ Jumlah pneumatofor di dalam mikroplot

Persamaan 3

Hasil dari persamaan 2 diatas merupakan nilai dari estimasi biomasa pneumatofor kemudian dikalikan dengan faktor konversi karbon, faktor konversi karbon biasanya menggunakan angka 0.39. Setelah itu dibagi dengan luas area kuadrat $\left(m^{2}\right)$.

$\mathrm{C}$ Pneu $\left(\mathrm{Kg} \frac{\mathrm{C}}{\mathrm{m}^{2}}\right)=\frac{\text { Estimasi biomasa pneumatofor } x \text { Faktor konversi } \mathrm{C}(0.39)}{\text { Luas area dari kudrat }\left(\mathrm{m}^{2}\right)}$

Keterengan :

C Pneu : Karbon Pneumatofor

C : Karbon

Persamaan 4

Serapan karbondioksida pada pneumatofor dapat diperoleh melalui perhitungan perkalian Total Karbon dengan Faktor Konversi Karbon (3.67). 3.67 
merupakan angka konversi unsur karbon (C) ke $\mathrm{CO} 2$ (masa atom $\mathrm{C}=12$ dan $\mathrm{O}=16, \mathrm{CO} 2$ $\Rightarrow \quad(1 \times 12)+(2 \times 16)=44 ; \quad$ konversinya $\Rightarrow$ $(44: 12)=3.67)$.

Serapan

$\mathrm{CO}_{2}$ Pneu=Total $\mathrm{C} \times \mathrm{C}$ conversion factor (3.67)

\section{HASIL DAN PEMBAHASAN}

\section{Berat Kering Pneumatofor Avicennia marina}

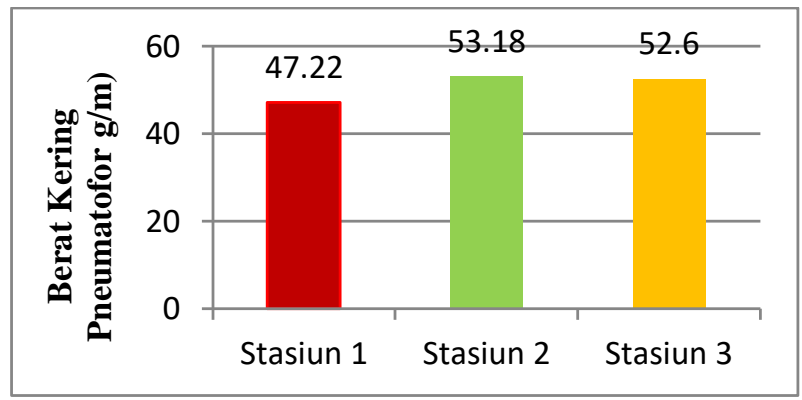

Gambar 2. Nilai Total Berat Kering Pneumatofor Di Setiap Stasiun Di Desa Darunu

Berdasarkan gambar 2 di atas nilai total berat kering pneumatofor tertinggi terdapat di Stasiun 2 sebanyak $53,18 \mathrm{~g} / \mathrm{m}^{2}$, diikuti pada stasiun 2 sebanyak $52,60 \mathrm{~g} / \mathrm{m}^{2}$, dan nilai terendah terdapat di Stasiun 1 sebanyak $47,22 \mathrm{~g} / \mathrm{m}^{2}$.

\section{Biomasa Pneumatofor Avicennia marina}

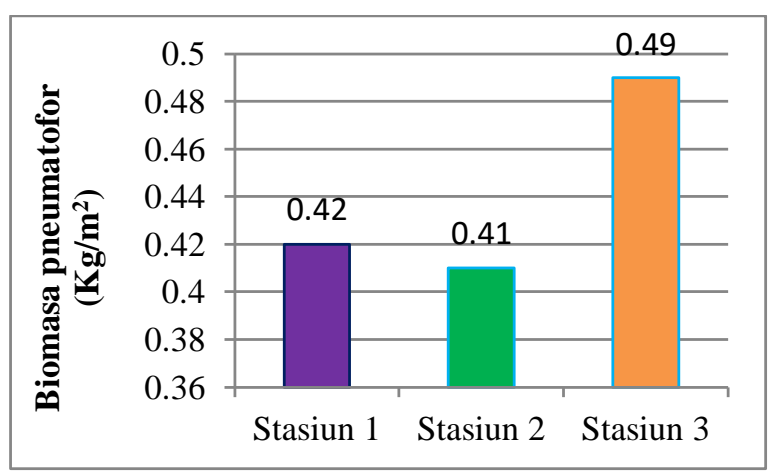

Gambar 3 . Nilai Rata-rata Biomasa

Pneumatofor Di Setiap Stasiun Di Desa Darunu

Berdasarkan gambar 3 di atas nilai rata-rata biomasa pneumatofor tertinggi di temukan di Stasiun 3 sebanyak $0,49 \mathrm{Kg} / \mathrm{m}^{2}$, diikuti stasiun 1 sebanyak $0,42 \mathrm{Kg} / \mathrm{m}^{2}$, dan nilai terendah terdapat di Stasiun 2 sebanyak $0,41 \mathrm{Kg} / \mathrm{m}^{2}$. Nilai biomasa akar berkorelasi dengan diameter batang, dimana semakin besar diameter batang semakin besar juga biomasa akar, begitu juga sebaliknya (Baderan, 2017). Dalam arti setiap peningkatan diameter atau tinggi total pohon selalu diikuti oleh peningkatan biomasa pada setiap bagian pohon (Yamani, 2013).

Karbon Pneumatofor Avicennia marina di Desa Darunu Kecamatan Wori Kabupaten Minahasa Utara

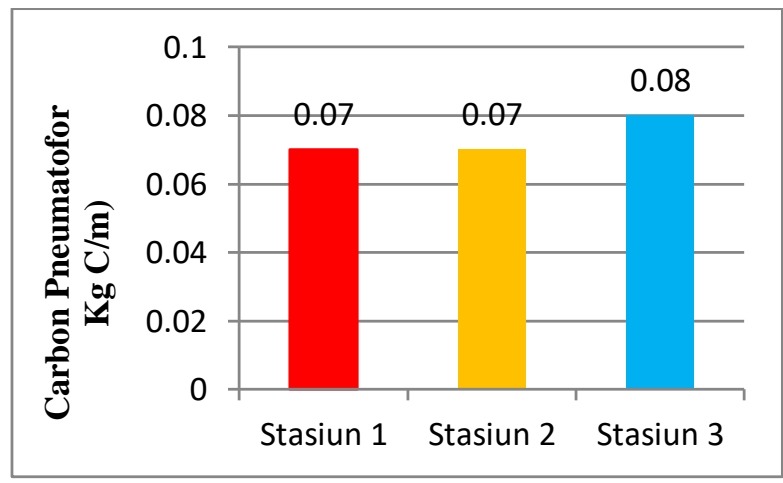

Gambar 4. Nilai Rata-rata Karbon

Pneumatofor Di Setiap Stasiun Di Desa Darunu

Hasil estimasi karbon pneumatofor pada Gambar 4 di atas terlihat total nilai karbon pneumatofor paling tinggi terdapat di Stasiun 3 sebanyak $0.08 \mathrm{Kg} \mathrm{C} / \mathrm{m}^{2}$. Sedangkan nilai karbon pneumatofor paling rendah terdapat di stasiun 1 dan stasiun 2 sebanyak $0.07 \mathrm{Kg} \mathrm{C} / \mathrm{m}^{2}$.

\section{Serapan $\mathrm{CO}_{2}$ Pneumatofor di Desa Darunu Kecamatan Wori}

Menurut Murdiyarso, et al. (1999), potensi penyerapan gas karbondioksida $\left(\mathrm{CO}_{2}\right)$ diperoleh melalui perhitungan dan perkalian kandungan karbon terhadap besarnya serapan karbondioksida $\left(\mathrm{CO}_{2}\right)$. 


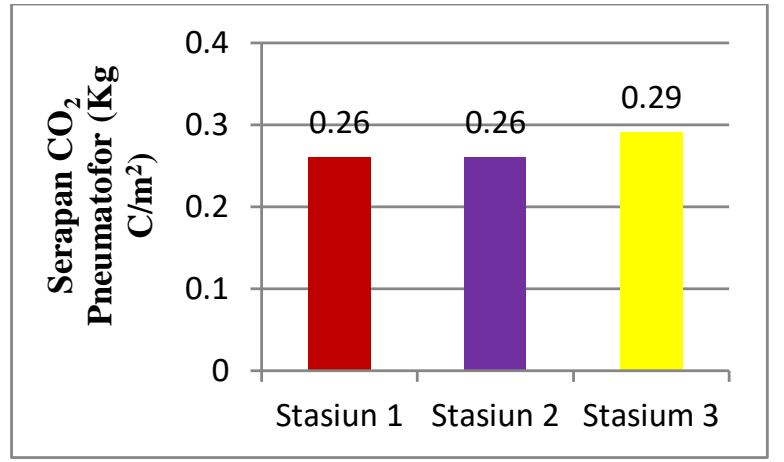

Gambar 5. Nilai Rata-rata Serapan $\mathrm{CO}^{2} \mathrm{Di}$ Setiap Stasiun Di Desa Darunu

Hasil estimasi serapan $\mathrm{CO}_{2}$ pada Gambar 5 di atas terlihat total nilai serapan $\mathrm{CO}_{2}$ paling tinggi terdapat di Stasiun 3 sebanyak $0,29 \mathrm{Kg} \mathrm{C} / \mathrm{m}^{2}$. Sedangkan nilai serapan $\mathrm{CO}_{2}$ paling rendah terdapat di 2 stasiun yaitu stasiun 1 dan stasiun 2 sebanyak $0.26 \mathrm{Kg} \mathrm{C} / \mathrm{m}^{2}$. Perbedaan nilai simpanan karbon pada setiap stasiun disebabkan oleh perbedaan jumlah berat akar, biomasa akar, kesuburan tanah, dan lokasi tempat tumbuh. Sugirahayu dan Rusdiana (2011) menyatakan hal-hal yang mempengaruhi perbedaan kandungan karbon pada mangrove yaitu faktor lingkungan tempat dimana mangrove tersebut tumbuh, kesuburan tanah yang ditumbuhi, kerapatan, jenis, dan umur dari tanaman. Hal ini sesuai dengan pernyataan Hariah dan Rahayu (2007) menjelaskan bahwa ekosistem yang memiliki kerapatan mangrove yang tinggi akan memiliki biomasa dan simpanan karbon yang tinggi, sebaliknya ekosistem dengan kerapatan yang rendah akan memiliki biomasa dan estimasi simpanan karbon rendah. Dimana semakin besar biomasa pohon maka kandungan dan serapan karbon juga semakin tinggi, ketika mangrove mengalami pertumbuhan maka karbondioksida yang ada di atmosfer akan diserap oleh tumbuhan dan disimpan dalam bentuk biomasa yang akan disimpan pada akar, batang dan daun tumbuhan itu sendiri. Sehingga semakin besar kemampuan mangrove dalam menyerap karbon maka potensi dalam mengurangi jumlah emisi karbon di atmosfer semakin meningkat (Baderan, 2017).

Hasil penelitian menunjukan bahwa nilai rata-rata serapan karbon pneumatofor $A$. marina di Desa Darunu Kecamatan Wori
Kabupaten Minahasa Utara adalah sebesar $0,28 \mathrm{Kg} \mathrm{C} / \mathrm{m}^{2}$, Dibandingkan dengan penelitian simpanan karbon akar Kristanti (2019) di Desa Tambaan, Kecamatan Panggungrejo, Pasuruan, Jawa Timur yaitu sebesar $12,65 \mathrm{Kg} \mathrm{C} / \mathrm{m}^{2}$. Kemudian penelitian simpanan karbon akar Hermalingga $d k k$. (2020) di Pulau Payung, Kabupaten Banyuasin yaitu sebesar 33,58 tonC/ha. Perbedaan nilai simpanan karbon disebabkan oleh perbedaan jumlah biomasa pohon, kesuburan tanah, dan daya serap vegetasi yang berbeda (Ati et al., 2014). Sedangkan biomasa menurut Rachmawati et al. (2014) mangrove dipengaruhi oleh kerapatan, diameter, tinggi, dan berat jenis kayu.

\section{KESIMPULAN}

Berdasarkan hasil penelitian, maka dapat disimpulkan bahwa nilai serapan $\mathrm{CO}_{2}$ pneumatofor $A$. marina yang tertinggi terdapat pada 2 stasiun yaitu stasiun 2 dan 3 dengan nilai $0,29 \mathrm{Kg} \mathrm{C} / \mathrm{m}^{2}$. Sedangkan hasil estimasi potensi serapan $\mathrm{CO}_{2}$ terendah terdapat pada stasiun 1 dengan nilai $0,26 \mathrm{Kg}$ $\mathrm{C} / \mathrm{m}^{2}$. Sehingga diperoleh nilai rata-rata serapan $\mathrm{CO}_{2}$ dari setiap stasiun di Desa Darunu Kecamatan Wori Kabupaten Minahasa Utara yaitu sebesar $0,28 \mathrm{Kg} \mathrm{C} / \mathrm{m}^{2}$.

\section{DAFTAR PUSTAKA}

Ati, R.N.A., Rustam, A., Kepel, T.L., Sudirman, N., Astrid, M., Daulat, A., Mangindaan, P., Salim, H.L. \& Hutahaean, A.A., 2014. Stok Karbon dan Struktur Komunitas Mangrove sebagai Blue Carbon di Tanjung Lesung, Banten.Jurnal Segara, 10(2):98-171.

Bachmid, F., Sondak, C.F.A. dan Kusen, J.D.K. 2018. Estimasi penyerapan karbon hutan mangrove Bawoho, Kelurahan Tongkaina, Kecamatan Bunaken. Jurnal Pesisir dan Laut Tropis 1(1): 8-13

Bachmid, F., Schaduw, J.N.W., Sondak, C.F.A, Rembet, U.N.W.J., Mandagi, S.V., Sumilat, D.A. dan Luasunaung, 
A. 2020. Potensi penyerapan karbon hutan bakau di Desa Serawet Kuala Batu, Likupang Timur, Kabupaten Minahasa Utara. Jurnal IImiah Platax 8(2): 152-158

Baderan, D.W.K. 2017. Serapan Karbon Hutang Mangrove Gorontalo. Yogyakarta.

Dahuri, R.,J. Rais., S. P. Ginting dan M. J. Sitepu. 1996. Pengelolaan Sumber Daya Wilayah Pesisir dan Lautan Secara Terpadu. PT. Pradnya Paramita. Jakarta.

Donato, D. C., Kauffman, J. B., Murdiyarso, D., Kurnianto, S., Stidham, M., dan Kanninen, M. 2011. Mangroves among the most carbon-rich forests in the tropics. Nature Geoscience, 4 (5) : 293-297.

EPA. 2008. Carbon Sequestration in Agriculture and Forestry. www.epa.gov/sequestration/index.ht $\underline{\mathrm{ml}}$

Eshel, A. dan Grunzweig J.M. 2012. RootShoot Allometry of Tropical Forest Trees Determined in A Large-Scale Aeroponic System. Annals of Botany 112:291 - 296.

Hairiah, K. dan Rahayu, S. 2007. Pengukuran 'karbon tersimpan' di berbagai macam penggunaan lahan. World Agroforestry Centre. ICRAF, SEA Regional Office, University of Brawijaya, Indonesia.

Halidah. 2014. Avicennia marina (Forssk). Vierh. Jenis Mangrove Yang Kaya Manfaat. Balai Penelitian Kehutanan Makassar. Info Teknis EBONI. Vol. 11 No 1, Mei 2014 : 37 $-44$

Hermialingga S, Suwignyo R.A, Ulqodry T.Z. 2020. Potensi Simpanan Karbon Pada Biomasa Tegakan dan Akar Mangrove Di Kawasan Lindung Pantai Pulang Payung, Kabupaten Banyuasin. J. Segara Vol.16. http://ejournal- balitbang.kkp.go.id/index.php/segar a.

Howard, J., Hoyt, S., Isensee, K., Pidgeon, E., \& Telszewski, M. (eds.). 2014. Coastal Blue Carbon: Methods for assessing carbon stocks and emissions factors in mangroves, tidal salt marshes, and seagrass meadows. Conservation International, Intergovernmental Oceanographic Commission of UNESCO, International Union for Conservation of Nature. Arlington, Virginia, USA.

IPCC. (2007). Climate Change 2007 Synthesis Report. Intergovernmental Panel on Climate Change [Core Writing Team IPCC. https://doi.org/10.1256/0043165023 20517344.

Jana, B.P., S. Biswas, M. Majumder, P. K. Roy and A. Mazumdar, 2009. Carbon sequestration rate and aboveground biomass carbon potential of four young species. Journal of Ecology and Natural Environment Vol. 1(2), pp. 015-024.

Kathiresan K,Gomathi V, Anburaj R, Saravanakumar K, Asmathunisha N, Sahu S.K, Shanmugaarasu V, Anandhan S. 2013. Carbon sequestration potential of mangroves and their sediments in southeast coast of India. Faculty of Marine Sciences, Annamalai University, Parangipettai. India.

Kauffman, J. Boone, \& Daniel C. Donato.Protocols for the measurement, monitoring and reporting of structure, biomass, and carbon stocks in mangrove forests. Bogor, Indonesia: CIFOR, 2012.

H. Kordi K.M, Ghufron. 2012. Ekosistem Mangrove; Potensi, fungsi, dan Pengelolaan. Jakarta: Rineka Cipta. Odum, E.P.. 1971. Fundamental Of Ecology. WB. Sander Company, USA. 
Kristanti, M, Lilik. 2019. Analisis Simpanan $\mathrm{CO}_{2}$ Pada Akar, Daun dan Sedimen Mangrove Avicennia marina Di Kawasan Mangrove Desa Tambaan, Kecamatan Panggungrejo, Pasuruan, Jawa Timur. Skripsi. Tidak Dipublikasikan. FPIK Universitas Brawijaya, Malang. $47 \mathrm{Hal}$.

Murdiyarso, D. 1999. Perlindungan Atmosfer Melalui Perdagangan Karbon: Paradigma Baru Dalam Sektor Kebutuhan. Orasi IImiah Guru Besar Tetap IImu Atmosfer. Fakultas MIPA IPB. Bogor. $47 \mathrm{Hal}$.

Sugirahayu, L., dan O. Rusdiana. 2011. Perbandingan Simpanan Karbon Pada Beberapa Penutupan Lahan di kabupaten Paser, Kalimantan Timur Berdasarkan Sifat Fisik dan Sifat Kimia Tanahnya, Departemen Silvikultur, Fakultas Kehutanan IPB. 2930: 149-155.

Tidore, F. Rumengan, A.P., Sondak, C.F.A., Mangindaan, R.E.P., Runtuwene, H.C.C. dan Pratasik, S.B. 2018. Estimasi kandungan karbon (C) pada serasah daun mangrove di Desa Lansa, Kecamatan Wori, Kabupaten Minahasa Utara. Jurnal Pesisir dan Laut Tropis 2(1): 53-58

Tiolong, G.M., Rumengan, A.P., Sondak, C.F.A., Boneka, F.B., Mamangkey,
N.G.F. dan Kondoy, K.I.F. 2019. Estimasi karbon vegetasi mangrove di Kelurahan Pintu Kota, Kecamatan Lembeh Utara, Kota Bitung. Jurnal Pesisir dan Laut Tropis 7(2): 98-103

UNFCCC, "Historic Paris Agreement on Climate Change: 195 Nations Set Path to Keep Temperature Rise Well Below 2 Degrees Celsius," Website UNFCCC, 2015.

Verisandria, R.J., Schaduw, J.N.W., Sondak, C.F.A., Ompi, M., Rumengan, A.P. dan Rangan, J.C. 2018. Estimasi potensi karbon pada sedimen ekosistem mangrove di pesisir Taman Nasional Bunaken bagian Utara. Jurnal Pesisir dan Laut Tropis 1(1): 81-97

Windusari, Y., N. A. P. Sari, I. Yustian dan H. Zulkifli. 2012. Dugaan Cadangan Karbon Biomasa Tumbuhan Bawah dan Serasah di Kawasan Suksesi Alami pada Area Pengendapan Tailing Pt Freeport Indonesia. Biospecies. 5(1) : 22-28.

Yamani, Ahmad. 2013. Analisis Kadar Hara Makro dalam Tanah pada Tanaman Agroforestri di Desa Tambun Raya Kalimantan Tengah. Fakultas Kehutanan. Universitas Lambung Mengkurat. Kalimantan Selatan. 